University of Rhode Island

DigitalCommons@URI

Mechanical, Industrial \& Systems Engineering

Faculty Publications

Mechanical, Industrial \& Systems Engineering

2021

\title{
Tornado-strength winds interacting with a highway overpass
}

D.M.L. Meyer

University of Rhode Island, dmmeyer@uri.edu

Alex Ensign

Follow this and additional works at: https://digitalcommons.uri.edu/mcise_facpubs

The University of Rhode Island Faculty have made this article openly available.

Please let us know how Open Access to this research benefits you.

This is a pre-publication author manuscript of the final, published article.

Terms of Use

This article is made available under the terms and conditions applicable towards Open Access

Policy Articles, as set forth in our Terms of Use.

Citation/Publisher Attribution

Meyer, D. M. L., \& Ensign, A. (2021). Tornado-strength winds interacting with a highway overpass. Physics of Fluid, 33, 107116. https://doi.org/10.1063/5.0065233

Available at: https://doi.org/10.1063/5.0065233

This Article is brought to you for free and open access by the Mechanical, Industrial \& Systems Engineering at DigitalCommons@URI. It has been accepted for inclusion in Mechanical, Industrial \& Systems Engineering Faculty Publications by an authorized administrator of DigitalCommons@URI. For more information, please contact digitalcommons-group@uri.edu. 
TITLE

Tornado-Strength Winds Interacting with a Highway Overpass

\author{
AUTHORS AND AFFILIATIONS \\ DML Meyer* and Alex Ensign $\dagger$ \\ * Corresponding author; Thermomechanics Laboratory, Mechanical Engineering, University of \\ Rhode Island (URI), Kingston, RI, USA, dmmeyer@uri.edu \\ † Fluid Imaging Technologies, Inc., Scarborough, ME, USA, alexensign18@gmail.com
}

\begin{abstract}
Analysis of tornado strength winds interacting with a highway overpass structure is presented with emphasis on air flow patterns above and under the bridge. Experiments were performed in a wind tunnel with the scaled geometry of an overpass. Velocity and dynamic pressure measurements were obtained independently at four locations as the overpass was rotated about its vertical axis between air flow angles of approach between $0^{\circ}$ and $90^{\circ}$, at $10^{\circ}$ increments. Lift and drag forces on the overpass geometry were also measured. To compare various highway overpass locations with the surroundings, the measured dynamic pressure and velocity, drag and lift forces, and drag coefficients at each of the locations and approach angles were examined. It was found that at all locations, the measured velocities never exceeded the freestream velocity of $190.2 \mathrm{ft} / \mathrm{s}(58 \mathrm{~m} / \mathrm{s} ; 130 \mathrm{mph})$, with the maximum Re occurring above the overpass and between the I-beams. A theoretical maximum pressure drop for the tornado center was calculated to be 0.5 psi for an Enhanced Fujita 2 (EF2) scale tornado and compared with the highest pressure drop of $0.278 \mathrm{psi}$, determined from the experiments. Calculated pressure coefficients $C_{p}$ were mostly $<0$ and some close to one dynamic head less than ambient. The drag coefficients $C_{d}$
\end{abstract}


remain primarily in the laminar region with later transition to turbulence. Using experimental data from the literature, drag forces on an average size man in crouching and laying positions between the overpass I-beams section were determined to be a maximum of $31 \mathrm{lb}$.

\section{INTRODUCTION}

During a tornado, areas under an overpass seem like suitable places for people to seek refuge. It is suggested however, that this is ill-advised (1-3) creating a dangerous situation, due in part to the localized air pressures developed in these spaces from the high-strength wind effects experienced during a tornado.

Several reasons for discouraging the public from seeking refuge from a tornado in areas under a highway overpass have been suggested in news and web-based articles $(1,2,4,5)$. While there are many, the primary reasons have been focused on the high speeds of the debris field, the potential air velocity increase through the smaller cross-sectional areas under the overpass, the flat concrete walls without places in which to anchor, and the abrupt changes in wind direction as a tornado passes over an overpass structure. Other reasons include hampering of traffic through these areas, including vehicles parked in the vicinity of an overpass prohibiting emergency services dispatch, and blocking transportation routes out of the tornado-event area. To date, statistics identify deaths occurring due in part to some individuals and/or vehicles using areas beneath overpasses as shelters during tornados $(1,3,6,7)$.

There have been previous wind tunnel experiments and modeling examining tornado vortices and surface interactions of tornadoes $(8,9)$. The current paper presents results of wind tunnel 
experiments that are specific to a highway overpass structure. While there are countless structures in which tornado interactions may occur, the highway overpass was chosen to examine the pressure, velocity and force fields in the vicinity of such structures since data currently is minimal.

The vertical length scale of interest is less than 10 meters above the atmospheric ground level

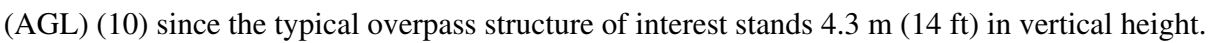
With regard to damage caused by tornado events, several interesting papers on the effects of the vortex corner flow, where the air stream turns vertically upward, highlight the importance of the near-surface radial inflow of tornadic winds in computer modeling (11-14). Here also, a tornado dimensionless parameter such as (corner) swirl ratio $(14,15)$ coupled with near-surface velocities have been found to affect the increase or decrease in intensity of a tornado (13).

In the current work, the tornadic winds are assumed constant with the effects of a developing tornado and frictional losses neglected, as is the vertical wind component $(10,16,17)$ and structural modal analyses (18). The experiments presented for freestream Reynolds number air flows of 1.1E06, utilize straight-line wind tunnel velocities with varying angles of approach of the winds on the highway overpass structure. The wind tunnel straight-line velocities differ from a true tornado and complex simulations, in which complicated and interrelated two and threedimensional effects consist of high variability in the far-field and near-field environments (19). Additionally, terrain of varying heights and slopes, over which a tornado passes, strongly influence a vortex traversing the terrain slope both upwards and downwards (20). 
Experimental air dynamic pressures and corresponding air velocities in several sections under and above a two-lane bridge crossing a six-lane highway are examined, for a tornado. Scaled wind tunnel experiments and analytical methods, in particular in the areas in and below the overpass abutment or I-beams, the center of a travel lane under the overpass and the location immediately above the overpass, are the locations of interest. To distinguish whether various highway overpass locations have adverse conditions compared with the surroundings, the measured dynamic pressure, measured drag and lift forces, and drag coefficients at each of the four locations and angles of approach were examined. In addition, comparison of a calculated pressure drop using the experimental data, with a theoretical maximum pressure drop is presented along with the drag force on a person under the overpass.

\section{METHODOLOGY}

\section{Governing Equations}

The fluid mechanics of the air flow of a tornado about a highway overpass is governed by the Navier-Stokes and Continuity equations. The constitutive equation for a Newtonian fluid, the Navier-Poisson Law, may be derived from the total stress, assumed symmetric:

$$
\sigma_{i j=-P \delta_{i j}+C_{i j k l} D_{k l}}
$$

where $\mathrm{C}_{\mathrm{ijkl}}$ is Lamé's equation, and the rate of deformation tensor $\mathrm{D}_{\mathrm{kl}}$ is symmetric. Lamé's equation,

$$
C_{i j k l}=\lambda \delta_{i j} \delta_{k l}+\mu\left(\delta_{i k} \delta_{j l}+\delta_{i l} \delta_{j k}\right)
$$

where $\lambda$ and $\mu$ are independent parameters characterizing absolute viscosity $\eta$. Inserting Eq. (2) into Eq. (1) in direct notation produces the constitutive equation for Newtonian fluids, the Navier-Poisson Law: 


$$
\underline{\sigma}=-P \underline{I}+\lambda \operatorname{tr}(\underline{D}) \underline{I}+2 \mu \underline{\mathrm{D}}
$$

Inserting the constitutive Eq. (3) into the field equation known as Cauchy's Equation of Motion from the Principle of Virtual Work,

$$
\bar{\nabla} \cdot \sigma+\rho \bar{g}=\rho \bar{a}
$$

where $\rho$ is density, $\rho \bar{g}$ and $\rho \bar{a}$ are the body force per unit volume and force due to acceleration per unit volume, respectively. The resulting Navier-Stokes (N-S) equations are:

$$
\frac{D(\rho \bar{V})}{D t}=-\bar{\nabla} p+(\lambda+\mu) \bar{\nabla}(\bar{\nabla} \cdot \bar{V})+\mu \bar{\nabla}^{2} \bar{V}+\rho \bar{g}
$$

\section{Air Compressibility}

In order to determine whether the N-S equations apply to compressible or incompressible effects on the flow in the vicinity of the overpass, the magnitude of the Mach number (Ma) is the criterion. The dimensionless Mach number $\mathrm{Ma}=\mathrm{V} / \mathrm{c}$ represents the ratio of inertial to compressibility effects, where $\mathrm{V}$ is the fluid velocity and $\mathrm{c}$ is the speed of sound in air. The incompressible assumption is valid for $\mathrm{Ma}<0.3(21,22)$. For a constant air flow and an average air temperature of $23.9^{\circ} \mathrm{C}(297.0 \mathrm{~K})$, the sound speed in air at this temperature is approximately $345 \mathrm{~m} / \mathrm{s}(21)$. For a height of $4.3 \mathrm{~m}$ to the top of a full-scale overpass, actual data of tangential wind speeds varying with radii, as functions of elevations above ground level (23-25) were used to calculate the Mach number for an actual tornado. Corresponding to elevations of 5 to $10 \mathrm{~m}$, the wind speeds were estimated from this data to be between 30 and $60 \mathrm{~m} / \mathrm{s}$, which gives a Mach number range between 0.087 and 0.174 . For the wind tunnel air speed of $190.2 \mathrm{ft} / \mathrm{s}(58 \mathrm{~m} / \mathrm{s})$, the Mach number was 0.168 . In the actual tornado data and that for the wind tunnel air speeds, the Mach numbers are below 0.3, allowing for the incompressible assumption in the governing N-S 
equations. Expanding the left-hand side of Eq. (5) and eliminating the term applicable to compressibility $(\lambda+\mu) \bar{\nabla}(\bar{\nabla} \cdot \bar{V})$, reduces the equation to the following for incompressible flow:

$$
\rho\left(\frac{\partial \bar{V}}{\partial t}+\bar{V}(\bar{\nabla} \cdot \bar{V})\right)=-\bar{\nabla} p+\mu \bar{\nabla}^{2} \bar{V}+\rho \bar{g}
$$

\section{$\underline{\text { Windspeed Classification }}$}

As mentioned in the previous section, the freestream velocity in the wind tunnel was $190.2 \mathrm{ft} / \mathrm{s}$ $(58 \mathrm{~m} / \mathrm{s} ; 130 \mathrm{mph})$ which is in the wind classification for tornados on the Fujita scale of F2, ranging between $53-72 \mathrm{~m} / \mathrm{s}(118-161 \mathrm{mph})(26,27)$. The experimental velocity was also within the range of the updated classification Enhanced Fujita (EF) tornado scale of EF2 (26-30) ranging between approximately $49-61 \mathrm{~m} / \mathrm{s}(110-137 \mathrm{mph})(30)$. The $58 \mathrm{~m} / \mathrm{s}$ freestream velocity in the wind tunnel corresponds to a freestream Re number of 1.1E06, for a constant air density $\rho$ $=1.1857 \mathrm{~kg} / \mathrm{m}^{3}(21)$, a constant dynamic viscosity $\mu=1.8 \mathrm{E}-05 \mathrm{~N} \cdot \mathrm{s} / \mathrm{m}^{2}(21)$, and using the hydraulic diameter of $0.295 \mathrm{~m}$ of the wind tunnel test section. The average measured temperature throughout the experiments in the vicinity of the wind tunnel was approximately $23.9^{\circ} \mathrm{C}\left(75^{\circ} \mathrm{F}\right)$.

\section{$\underline{\text { Dimensional Analysis }}$}

Geometric similarity is essential in appropriately scaling full-size tornado-strength winds in the wind tunnel experiments. To do so, the N-S Eq. (6) are nondimensionalized using the following change of variables represented by the dimensionless starred $(*)$ terms:

$$
x_{i}=x_{i}^{*} L ; t=t^{*} \frac{L}{V} ; v_{i}=v_{i}^{*} V ; p=p^{*} \rho V^{2}+p_{f s},
$$

where $\mathrm{i}=1,2$ and 3, $\rho$ is density and $p_{f s}$ is the freestream dynamic pressure. The pressure

coefficient (22), $p^{*}=\frac{p-p_{f s}}{\rho V^{2}}$, also known as the dimensionless Euler number (Eu) (31), is a 
useful ratio of pressure to inertial forces. Inserting the change of variables into the N-S Eq. (6) with g, $\rho$ and $\mu$ as constants, gives the dimensionless N-S revealing additional dimensionless parameters Froude number (Fr) and Reynolds number $(\mathrm{Re})$ :

$$
\frac{\partial \bar{V}^{*}}{\partial t^{*}}+\bar{V}^{*}\left(\bar{\nabla}^{*} \cdot \bar{V}^{*}\right)=-\bar{\nabla}^{*} p^{*}+\frac{1}{R e} \bar{\nabla}^{* 2} \bar{V}^{*}+\frac{1}{F r}
$$

The Re number provides a ratio of inertial to viscous effects and is important for dynamic similarity. The Fr number is also important for dynamic similarity when external body forces such as gravitational effects are important, as in free-surface flows $(21,31)$ or density-stratified flows, for examples. Gravitational effects associated with Fr in the current work however, are neglected.

The important fluid parameters are $\Delta \mathrm{p}_{\mathrm{c}}, \mathrm{V}, \rho, \mu, \mathrm{L}, \mathrm{F}_{\mathrm{d}}, \mathrm{F}_{\mathrm{l}}$ and $\mathrm{A}$, where $\Delta \mathrm{p}_{\mathrm{c}}$ is the difference between the measured dynamic pressure and the free stream dynamic pressure $\Delta \mathrm{p}_{\mathrm{c}}=\mathrm{p}-\mathrm{p}_{\mathrm{fs}}$. The other parameters are velocity $\mathrm{V}$, density $\rho$, dynamic viscosity $\mu$, a length scale in the flow direction $\mathrm{L}$, drag force $\mathrm{F}_{\mathrm{d}}$, lift force $\mathrm{F}_{\mathrm{l}}$ and area $\mathrm{A}$, in this case, the frontal area affected by the air flow.

Using the Buckingham Pi Theorem (32) and the fluid parameters above, the following dimensionless Pi groups result:

$$
R e=\frac{\rho V L}{\mu} ; C_{p}=\frac{\Delta p_{c}}{\frac{1}{2} \rho V^{2}} ; C_{d}=\frac{F_{d}}{\frac{1}{2} \rho V^{2} A} ; C_{l}=\frac{F_{l}}{\frac{1}{2} \rho V^{2} A}
$$

The Pi groups Eq. (8) are identified as Reynolds number (Re), Euler number (Eu) (31), or as indicated earlier, more often called the local pressure coefficient $\left(C_{p}\right)(22,25)$, drag $\left(C_{d}\right)$ and lift $\left(\mathrm{C}_{1}\right)$ coefficients, respectively. 
For dynamically similar air flows, the Re and Ma numbers must be within the same order of magnitude $(21,22)$. Since the flow has been found to be incompressible for both the experiments and actual tornadic winds at the same elevation, the requirement for dynamic similarity of Ma was met. With the wind tunnel $\mathrm{Re}=1.1 \mathrm{E} 06$ based on the freestream velocity of $190.2 \mathrm{ft} / \mathrm{s}(58$ $\mathrm{m} / \mathrm{s}$ ), which falls within the range of an EF2 scale tornado, dynamic similarity of the scaled geometry matches the Re for an actual EF2 scale tornado $(26,28,33,34)$.

\section{Experimental Setup}

The wind tunnel used for the experiments (Aerolab EWT, Jessop MD) is in the shape of a converging-diverging nozzle (Figure 1a).

Figure 1: (a) Wind tunnel with test section and air flow direction; (b) Scaled geometry at 0 degrees with Pitot-static tube parallel to air flow direction, as seen from test section window.

A large fan in the exit section draws air through the tunnel. The test area is located at the throat section and is 0.61 meters long (24 in) with cross-sectional dimensions $0.295 \mathrm{~m}$ x $0.295 \mathrm{~m}(11 \mathrm{5} / 8$ in $\mathrm{x} 11 \frac{5}{8}$ in). The fan is powered by a variable frequency drive motor and has a top speed of approximately $65 \mathrm{~m} / \mathrm{s}(145 \mathrm{mph})$.

Aerodynamic forces of lift $\left(\mathrm{F}_{\mathrm{l}}\right)$ and drag $\left(\mathrm{F}_{\mathrm{d}}\right)$ acting on the scaled geometry were measured using a strain gage system located beneath the test section of the wind tunnel. A single mounting post extends up through the floor of the wind tunnel to which the overpass structure was attached, 
thus ensuring all forces were detected by the system. The strain gage system takes readings through voltages. These signals were sent through a filter and calibration device before being recorded by data acquisition software TracerDAQ (Measurement Computing, Corp. Norton, MA). A separate force measuring device was necessary to establish the relationship between units of force and voltage.

An Extech HD 350 (Extech Instruments Corp., Waltham, MA) anemometer/manometer was used with a Pitot-static tube to measure velocity and dynamic pressure independently of one another. The anemometer functions by heating a wire inside the HD 350 and using the airflow from the stagnation port of the Pitot-static tube to cool it. The amount of energy needed to keep the wire at constant temperature determines velocity. All calculations and conversions were executed by the Extech device.

The scaled geometry of a typical full-scale, standard, highway overpass carrying two lanes over a six-lane interstate $(35,36)$ used in this experiment was designed using computer-aided design (CAD) software (DS SolidWorks, Corp., Waltham, MA) and was fabricated using a 3D printer (Stratasys Ltd., Eden Prairie, MN). The embankment that normally surrounds and provides support for the overpass abutments were fabricated by hand using 0.020 -inch sheet metal. To mount the scaled geometry in the wind tunnel test section, a flat plate sitting atop an aluminum post was constructed. The post extended through the floor of the test section directly into the force balance device. The flat plate was designed to imitate a road passing beneath the overpass. It was thin enough and extended far enough away from the overpass in both directions leading under the bridge that eddies created by the leading and trailing edges did not affect 
measurements. It was also elevated in order to avoid boundary layer effects caused by the tunnel floor.

In order to match a Reynolds number in the wind tunnel equivalent to that found in an EF2 scale tornado, the scale of the overpass geometry was approximately 1:217. In the orientation of the middle image of the structure in Fig. 2, the airflow is coming out of the page toward the reader, in the $\mathrm{x} 2$-direction using the coordinate system of the upper left image. A small slot was cut into the end on between the I-beam on the back side of the overpass labeled as Location 2, to allow for Pitot-static tube access to the interior directly under the overpass. The scaled geometry was rotated clockwise through angles of $0^{\circ}-90^{\circ}$, in $10^{\circ}$ increments with measurements of velocity, dynamic pressure, lift and drag forces recorded at each increment at the four locations identified in Fig. 2. In addition to the slot, a small hole was cut on the side of the overpass to allow for Pitot-static tube access when the geometry was rotated through the more extreme angles of $70^{\circ}$ $90^{\circ}$ degrees. All values in Fig. 2 are in meters.

Figure 2: A scaled geometry (1:217) of a standard highway overpass; Measurements taken at four locations: 1 - immediately above overpass, 2 - in between I-beams, 3 - immediately under Ibeams, and 4 - center of travel lane under overpass; The airstream direction is indicated with an arrow. Air flow is perpendicular to the overpass structure when the angle of approach $\phi=0^{\circ}$.

Prior to conducting experiments, the free stream velocity of the air passing through the wind tunnel test section was established. This was performed with the test section clear of structures 
other than the Pitot-static tube. In addition, the lift and drag forces caused by only the mounting system were determined so they could later be subtracted from those caused by the overpass.

\section{RESULTS AND DISCUSSION}

Experimental and analytical results are presented with discussion.

\section{Normalized Dynamic Pressure}

At all four locations and in the freestream, dynamic pressure measurements were taken at each angle of approach of the air flow to the overpass between $0^{\circ}$ and $90^{\circ}$, in $10^{\circ}$ increments.

Presented in Fig. 3 the dynamic pressure measurements have been normalized with the freestream measurement $\left(p_{\text {exp }} / 1 / 2 \rho V_{f s}^{2}\right)$. At location 1 above the overpass, with the air flow approaching the structure beyond an angle of $40^{\circ}$, the normalized pressure is nearly the same as the freestream measurement until reaching $90^{\circ}$. The opposite is true for the center travel lane of location 4 and below the I-beams at location 3, with decreasing normalized pressure after air flow angles of approach of $40^{\circ}$. The normalized pressures change in the area of location 2 between the I-beams from a low value of -0.008 psi to a maximum value of $0.300 \mathrm{psi}$, the latter occurring when the air flow approaches the overpass at an approach angle of $70^{\circ}$.

Figure 3: Dynamic pressure measurements normalized with the freestream for air flows approaching the overpass in $10^{\circ}$ increments from $0^{\circ}$ to $90^{\circ}$.

\section{Air Velocity Measurements}


Similar correlations are observed in Fig. 4, comparing the measured air flow velocities at the four locations and the freestream for varying approach angles. In all locations where velocity measurements were obtained, the velocities remained the same as, or below, the freestream velocity of $190.2 \mathrm{ft} / \mathrm{s}(58 \mathrm{~m} / \mathrm{s})$. Above the overpass (location 1$)$ the velocities are nearly the same as the freestream velocity between $50^{\circ}$ and $80^{\circ}$ angles of approach. Below the I-beams (location $3)$, the velocities also approach the freestream. This is also the case in the center travel lane (location 4) when the angles of approach are between $0^{\circ}$ and $40^{\circ}$. For anyone parked under the overpass, these nearly freestream velocities do not offer much protection from the tornadostrength winds, rather only the potential for reducing vehicle damage. Earlier it was stated that one of the main reasons for discouraging people from using an overpass for protection during a tornado was the potential for the air velocities to increase through the smaller cross-sectional areas under the overpass. If it is assumed that the locations under an overpass potentially display flows similar to a converging section, locations 2 and 3 in particular may not be the locations where an increase in airstream velocities would occur, at least based on the measurements obtained. Instead, if the airflows accelerate through the underpass sections with values greater than the freestream, these may occur at locations other than those where measurements were obtained in the current work.

Note that no velocity measurements were obtained for the $80^{\circ}$ angle of approach in the center travel lane (location 4) nor at the $90^{\circ}$ angle of approach, below the I-beams (location 3). 
Figure 4: Air velocity measurements obtained with flows approaching the overpass in $10^{\circ}$ increments from $0^{\circ}$ to $90^{\circ}$ and in the freestream.

\section{Theoretical Maximum Pressure Drop Calculation}

The maximum pressure drop $\Delta \mathrm{p}$ at the tornado center, where the location of low pressure resides was estimated using the expression of the thermodynamic speed limit $(37,38)$. The purpose is to compare the theoretical value to the maximum pressure drop value for the current experiments. The assumption used was that the tornado may be expressed as a Rankine vortex (23), a model for the distribution of wind in hurricanes and tornadoes characterized as a first approximation by an inner region rotating as a solid with decreasing wind speeds to ambient levels in the tornado outer portion $(25,39)$. The hydrostatic pressure deficit (40) may be expressed as the difference between the free stream pressure and the local pressure in the vicinity of the tornado center: $\Delta \mathrm{p}=$ $\mathrm{p}_{\mathrm{fs}}-\mathrm{p}$. The steady-state upper limit (41) or thermodynamic speed limit is therefore a result of the minimum pressure in a vortex, owed entirely to $\Delta \mathrm{p}$ and described by (40),

$$
\Delta \mathrm{p}=\mathrm{C}(\rho) V_{r}^{2}
$$

where $\mathrm{C}$ is a constant relevant to various vortex profiles, $\rho$ is density and $\mathrm{V}_{\mathrm{r}}$ is the maximum rotational windspeed. In the current calculation, the freestream velocity $\mathrm{V}_{\mathrm{fs}}$ was used as an estimate of the maximum rotational windspeed. It should be noted that maximum wind speeds in numerical simulations have been observed to exceed the thermodynamic speed limit $(42,43)$. For a Rankine vortex, $C=1.0(40,41)$. Using the mean wind tunnel air density $=1.94 \mathrm{E}-03$ $\operatorname{slug} / \mathrm{ft}^{3}\left(1.1857 \mathrm{~kg} / \mathrm{m}^{3}\right)$ and the freestream velocity $\mathrm{V}_{\mathrm{fs}}=190.2 \mathrm{ft} / \mathrm{s}(58 \mathrm{~m} / \mathrm{s})$, the theoretical maximum pressure drop $\Delta \mathrm{p}$ at the center of the tornado is $\Delta \mathrm{p}=0.5 \mathrm{lb} f / \mathrm{in}^{2}$. 
The value of $\Delta \mathrm{p}$ represents the minimum pressure below the ambient value at the center of the tornado. The $\Delta \mathrm{p}$ value is higher than the value of the maximum pressure drop of $0.278 \mathrm{psi}$ obtained in the current experiments which occurred between the I-beams (location 2) at a direct approach of $0^{\circ}$ of the air flow to the overpass. The experimental value of 0.278 psi shows the wind tunnel velocities fall into a range of an EF2 scale tornado at a radial distance from the tornado center where the theoretical maximum pressure drop would be $0.5 \mathrm{psi}$. The radial distribution $\mathrm{r}$ as a function of velocity $\mathrm{V}$ from the tornado center was examined by Hoecker (1960) (23) where the relation $\mathrm{Vr}^{\mathrm{k}}=$ constant was established for the range of $\mathrm{k}, 0.8 \leq \mathrm{k} \leq 1.6$ and where the constant is determined for each event (44).

\section{$\underline{\text { Reynolds Number }}$}

The Reynolds numbers $\left(\operatorname{Re}_{\mathrm{x}}\right)$ for the air flow as it approaches the overpass at varying angles of approach for the four locations that velocity measurements were obtained are shown in Fig. 5. The value $\mathrm{Re}_{\mathrm{x}}$ is the local Reynolds number whose length scale is the distance from the leading edge of the bridge at which the pressure and velocity measurements were obtained as the structure was rotated. This distance " $x$ " started at the leading edge of the bridge for the individual rotation angles and ended at the tip of each of the Pitot-static tube locations. These locations were estimated as the distance to the trailing edge minus twice the Pitot-static tube diameter $(0.003 \mathrm{~m})$ or $0.006 \mathrm{~m}$. Only the air flow $\mathrm{Re}_{\mathrm{x}}$ above the overpass (location 1$)$ for an angle of approach of $80^{\circ}$, is similar to the freestream Re. For location 2 between the I-beams, the $\operatorname{Re}_{\mathrm{x}}$ increases steadily with a small jump after an angle of approach of $70^{\circ}$. The $\mathrm{Re}_{\mathrm{x}}$ for location 3 
under the I-beams is fairly constant until an angle of approach of $70^{\circ}$, similar to that for location 4, the center travel lane.

Figure 5: Reynolds number $\operatorname{Re}_{\mathrm{x}}$ through the angles of approach at each of the four locations and the freestream Reynolds number Re.

\section{$\underline{\text { Pressure Coefficient }}$}

The pressure coefficient, $C_{p}=\frac{\Delta p_{c}}{\frac{1}{2} \rho V^{2}}(25)$, where $\Delta \mathrm{p}_{\mathrm{c}}=\mathrm{p}-\mathrm{p}_{\mathrm{fs}}$, is described as the difference between the measured and freestream dynamic pressures, and where $\mathrm{V}$ is the freestream velocity. The pressure coefficient relates the dynamic pressure at the various locations of the overpass structure to that of the ambient and is a unique function of the air flow direction relative to the structure (45). The values of $C_{p}$ at each of the four locations as a function of $\operatorname{Re}_{\mathrm{x}}$ are presented in Fig. 6. Most of the pressure coefficients are negative, meaning below the ambient pressure, and several are close to one dynamic head below ambient. Above the overpass (location 1) the greatest negative values of $C_{p}(-0.89$ and -0.9$)$ occur at angles of approach of $10^{\circ}$ and $40^{\circ}$, respectively, while the same is true between the I-beams (location 2) with negative $C_{p}(-0.96$, $0.90,-0.85$ ) for angles $0^{\circ}, 10^{\circ}$ and $20^{\circ}$, respectively. In each of these cases, the $\operatorname{Re}_{\mathrm{x}}$ is on the order of $10^{4}$, lower than the freestream $\operatorname{Re}\left(10^{6}\right)$. For below the I-beams (location 3 ) the most negative $C_{p}=-0.92$. In the center travel lane (location 4$)$ the greatest negative values of $C_{p}(-0.92$ to -0.95 ) occur at the higher angles of approach between $70^{\circ}$ and $80^{\circ}$ for $\operatorname{Re}_{\mathrm{x}}$ in the higher range of E05. The $C_{p}$ values in the vicinity of -1.0 are similar to those for a short building of height-tolength ratio of 0.1 (45). The overpass ratio in the current experiments is $0.0232 \mathrm{~m} / 0.182 \mathrm{~m}=$ 0.13. While estimates of $C_{p}$ are possible for certain common structures, the wind tunnel 
experiments presented here allow the $C_{p}$ values to be determined directly from experimental data on the overpass and its orientation with respect to the air flow direction.

Figure 6: Pressure coefficients as functions of Reynolds number Re $e_{x}$ with varying angles of approach

\section{$\underline{\text { Measured Drag and Lift Forces }}$}

The drag $\mathrm{F}_{\mathrm{d}}$ and lift $\mathrm{F}_{1}$ forces acting on the test geometry in the wind tunnel were measured using a strain gage system located beneath the test section of the tunnel and are presented in Fig. 7.

These values are used to determine the drag coefficients for scaling the forces on a full-size overpass.

Figure 7: Measured drag and lift forces on the overpass

Drag Coefficients

The important scaling of these experiments is particularly aimed at determining the drag coefficients $\mathrm{C}_{\mathrm{d}}$ for a full-scale overpass by using the above measured drag forces $\mathrm{F}_{\mathrm{d}}$, the measured freestream velocity $\mathrm{V}_{\mathrm{fs}}$ and the frontal areas $\mathrm{A}$ of the overpass for the varying angles of approach of the air flow, where $C_{d}=\frac{F_{d}}{\frac{1}{2} \rho V_{f s}{ }^{2} A}$. The calculated drag coefficients $\mathrm{C}_{\mathrm{d}}$ as a function of Re are presented in Fig. 8, for each angle of approach of the air flow. Here Re differs slightly from $\mathrm{Re}_{\mathrm{x}}$ used earlier. The value of $\mathrm{Re}$ is calculated using the length scale from the overpass leading edge to its trailing edge as the overpass is rotated through the angles of approach, rather 
than to the tip of the Pitot-static tube. Note that at a Re of approximately 5E05, the decrease in $\mathrm{C}_{\mathrm{d}}$ indicates that there is a transition to a turbulent boundary layer (21).

Figure 8: Drag coefficients for overpass as function of Reynolds number

\section{$\underline{\text { Analytical Drag Coefficient }}$}

As a means to check the drag coefficients obtained in the previous section, an analytical value of $\mathrm{C}_{\mathrm{d} \text {-analy }}$ is presented for the $0^{\circ}$ angle of approach, as an example for comparison. The analytical value is comprised of the sum of the drag coefficients for the overpass skin friction $\mathrm{C}_{\mathrm{df}}$, the three cylindrical pillars $\mathrm{C}_{\mathrm{d} 3 \mathrm{p}}$ and the overpass bridge $\mathrm{C}_{\mathrm{db}}$ section.

To obtain the skin friction drag coefficient, the skin friction drag force is determined with the overpass bridge portion described as a flat plate, following the work of Blasius (1908) (46) describing a steady boundary layer flow over a flat plate, and later confirmed by Goldstein (1933) (47). Schlichting (1979) (48) also offers a description for flow in the wake of a flat plate in which the drag force on the plate is the same as the loss of momentum due to friction $\mathrm{D}_{\mathrm{f}}$. An analytical skin friction drag force for a flat plate wetted on both sides is calculated using the following expression (46-48)

$$
D_{f}=1.328 b \rho V_{f s}^{2}\left(\frac{v l}{V_{f s}}\right)^{1 / 2}
$$

Where $\mathrm{b}$ is the overpass bridge span, $\rho$ is density, $\mathrm{V}_{\mathrm{fs}}$ is freestream velocity, $v$ is kinematic viscosity and 1 is the overpass bridge length in the flow direction. For an air flow angle of approach of $0^{\circ}$, the skin friction drag force of Eq. (10) becomes, 


$$
D_{f}=1.328(0.182 \mathrm{~m})\left(1.1857 \frac{\mathrm{kg}}{\mathrm{m}^{3}}\right)\left(58 \frac{\mathrm{m}}{\mathrm{s}}\right)^{2}\left(\frac{\left(1.518 E-05 \frac{\mathrm{m}^{2}}{\mathrm{~s}}\right)(0.0449 \mathrm{~m})}{58 \frac{\mathrm{m}}{\mathrm{s}}}\right)^{1 / 2}=0.1045 \mathrm{~N}
$$

The skin friction drag coefficient is obtained by,

$$
C_{d f}=\frac{D_{f}}{\frac{1}{2} \rho V_{f s}{ }^{2} A_{\text {wetted }}}=\frac{0.1045 \mathrm{~N}}{0.5\left(\left(1.1857 \frac{\mathrm{kg}}{\mathrm{m}^{3}}\right)\left(58 \frac{\mathrm{m}}{\mathrm{s}}\right)^{2} 2(0.182 \mathrm{m*0.0449m)})\right.}=0.003
$$

The drag coefficient for one of the three cylindrical pillars of the overpass is found to be 0.3 (21), such that for all three pillars,

$$
C_{d 3 p}=(3)(0.3)=0.9
$$

Finally, the overpass bridge treated as a rectangular plate, has a drag coefficient $C_{d b}=0.006$, or twice the skin friction drag coefficient (21). The analytical drag coefficient for the $0^{\circ}$ angle of approach then is the sum of the individual drag coefficients $C_{d f}+C_{d 3 p}+C_{d b}$ such that $C_{d-a n a l y}=$ $0.003+0.9+0.006=0.91$, which compares well to the drag coefficient of 0.9 obtained using experimental drag data also for $0^{\circ}$ air flow angle of approach.

\section{Drag Force Acting on a Person}

A report by Schmitt (1954) (49) for the U.S. Department of Defense, specifically the U.S. Navy, describes experiments of drag force on humans in a wind tunnel and calculated drag coefficients as functions of area $\mathrm{C}_{\mathrm{d}} \cdot \mathrm{A}$ for various positions and amounts of clothing. The subjects included 16 males ranging in age from 16 to 47 years, with an average weight of $162 \mathrm{lb}$. Experiments included five different positions of the test subjects: standing, sitting, laying down and two different squat or crouching positions. The data of the men fully clothed, laying down and one of the crouching positions were used to determine drag forces

$$
F_{d}=\frac{1}{2} \rho V^{2}\left(C_{d} A\right)
$$


where the values of $\mathrm{C}_{\mathrm{d}} \mathrm{A}$ are obtained from Schmitt (1954) and the velocities are those measured in the current experiments between the I-beams (location 2). The results of the calculations of Eq. (13) are presented in Fig. 9.

Figure 9: Drag force on average weight man (162 lbf) laying down or crouching in Location 2 between the I-Beams

The results presented from this work show that there are pressure and velocity distributions under and above a highway overpass that differ from the surroundings. It is however only the beginning of understanding the potential benefits and risks of using an overpass as shelter during a tornado. Other considerations require evaluation, such as the high speeds of the surrounding debris field, the abrupt changes in wind direction as a tornado crosses over an overpass structure and the potential for the airstream accelerating through portions of the underpass in which measurements have not yet been obtained.

\section{CONCLUSIONS}

Experimental dynamic pressures and velocities and drag and lift forces were measured on a scaled geometry of a highway overpass in a wind tunnel. Analytical values were determined and compared with experimental ones. The following considerations are reflected:

1) The measured dynamic pressures normalized with the freestream dynamic pressures show that when the air flow angles of approach to the overpass were between $50^{\circ}$ and $80^{\circ}$ 
just above the overpass, the normalized dynamic pressures were nearly the same as those of the freestream.

2) In all locations and angles of approach, the measured velocities remained the same as, or below the freestream velocity of $190.2 \mathrm{ft} / \mathrm{s}(58 \mathrm{~m} / \mathrm{s} ; 130 \mathrm{mph})$.

3) A theoretical maximum pressure drop for the tornado center was calculated to be $0.5 \mathrm{psi}$ for an EF2 scale tornado and compared with the maximum pressure drop of $0.278 \mathrm{psi}$ from the experimental data. The 0.278 psi value shows that the experimental velocities fall into a region of an EF2 scale tornado at a radial distance from the tornado center where the theoretical maximum pressure drop is 0.5 psi.

4) Nearly all of the pressure coefficients $C_{p}$ calculated are $<0$ and some nearly one dynamic head less than ambient.

5) The greatest $\operatorname{Re}_{\mathrm{x}}$ occurred above the overpass (location 1) after angles of approach of $40^{\circ}$, and from $60^{\circ}$ to $90^{\circ}$ for between the I-beams (location 2).

6) The drag coefficients $C_{d}$ remain in the laminar region until a Re of approximately 5E05 and air flow angle of approach of $80^{\circ}$, for which the boundary layer transitions to a turbulent one.

7) An analytical calculation for the drag coefficient at an angle of approach of $0^{\circ}$ was found to be $\mathrm{C}_{\mathrm{d}-\text { anal }}=0.91$ and compares well with the $\mathrm{C}_{\mathrm{d}}=0.9$ determined using the experimental data for the same approach angle.

8) The drag forces on a man weighing an average of $162 \mathrm{lb}_{\mathrm{f}}$ using experimental data for the person in crouching and laying positions between the I-beams (location 2), were determined to be the highest at air flow angles of approach of $40^{\circ}(29 \mathrm{lb})$ and $70^{\circ}(31$ $\mathrm{lb}_{\mathrm{f}}$. 


\section{ACKNOWLEDGMENTS}

For the first author, it has been not only an honor to call Prof. Frank M. White my colleague but also a dear friend. For many years we have exchanged ideas and had numerous discussions about the finer details of fluids. Using his fluids books in undergraduate and graduate courses has only enhanced concepts presented to students. The authors also wish to thank Dr. J. R. Torres and Mr. David C. Ponte of the Naval Undersea Warfare Center, Newport, RI, for their insightful discussions upon reading this manuscript.

\section{AUTHOR DECLARATIONS}

Conflicts of Interest

The authors have no conflicts to disclose.

\section{REFERENCES}

1. Miller DJ, Doswell III CA, Brooks HE, Stumpf GJ, Rasmussen EN. 1999, Highway overpasses as tornado shelters: Fallout from the 3 may 1999, Oklahoma/kansas violent tornado outbreak. Presented at National Weather Association, 24th Annual Meeting, http://www.spc.noaa.gov/faq/tornado/\#Safety, 1999, 2016 : Biloxi, MS:

2. Storm Prediction Center, NOAA/National Weather Service. The online tornado FAQ, frequently asked questions about tornadoes. http://www.spc.noaa.gov/faq/tornado/\#Safety 
3. Brown S, Archer P, Kruger E, Mallonee S. 2002. Tornado-related deaths and injuries on oklahoma due to the 3 may 1999 tornadoes. Weather and Forecasting. 17 : 343-53

4. Estrada H, Kiesling E. 2006, State-of-the-art protection against severe storms. Presented at AEI 2006, March 29, 2006 - April 1, 2006, 2006 : 34. Omaha, NE, USA: ASCE

5. Hammer B, Schmidlin TW. 2002. Response to warnings during the 3 may 1999 oklahoma city tornado: Reasons and relative injury rates. Weather and Forecasting. $17: 577-81$

6. Schmidlin TW, Hammer BO, Ono Y, King PS. 2009. Tornado shelter-seeking behavior and tornado shelter options among mobile home residents in the United States. Nat. Hazards. 48 : 191-201

7. Paulikas MJ, Schmidlin TW. 2017. US tornado fatalities in motor vehicles (1991-2015). Nat. Hazards. $87: 121-43$

8. Ying SJ, Chang CC. 1970. Exploratory model study of tornado-like vortex dynamics. J. Atmos. Sci. $27: 3-14$

9. Ward NB. 1972. The exploration of certain features of tornado dynamics using a laboratory model. J. Atmos. Sci. 29 : 1194-204

10. Hangan H, Romanic D, Jubayer C. 2019. Three-dimensional, non-stationary and nongaussian (3D-NS-NG) wind fields and their implications to wind-structure interaction problems. J. Fluids Struct. 91 : 102583 
11. Lewellen WS. 1962. A solution for three-dimensional vortex flows with strong circulation. J. Fluid Mech. 14 : 420-32

12. Lewellen WS, Lewellen DC, Sykes RI. 1997. Large-eddy simulation of a tornado's interaction with the surface. J. Atmos. Sci. 54 : 581-605

13. Lewellen DC, Lewellen WS. 2000. The influence of a local swirl ratio on tornado intensification near the surface. J. Atmos. Sci. $57: 527$

14. Lewellen DC, Lewellen WS. 2007. Near-surface vortex intensification through corner flow collapse. J. Atmos. Sci. 64 : 2195-209

15. Tang Z, Feng C, Wu L, Zuo D, James DL. 2018. Characteristics of tornado-like vortices simulated in a large-scale ward-type simulator. Boundary-Layer Meteorol. 166 : 327-50

16. Refan M, Hangan H. 2018. Near surface experimental exploration of tornado vortices. $J$. Wind Eng. Ind. Aerodyn. 175 : 120-35

17. Kawaguchi M, Tamura T, Kawai H. 2019. Analysis of tornado and near-ground turbulence using a hybrid meteorological model/engineering LES method. Int J Heat Fluid Flow. 80 : 108464

18. Karami M, Carassale L, Hangan H. 2020. Statistical and modal analysis of surface pressure fluctuations in tornado-like vortices. Physics of Fluids. 32 : 75109 
19. Flournoy MD, Coniglio MC, Rasmussen EN, Furtado JC, Coffer BE. 2020. Modes of storm-scale variability and tornado potential in VORTEX2 near- and far-field tornadic environments. Mon. Weather Rev. 148 : 4185-207

20. Satrio MA, Bodine DJ, Reinhart AE, Maruyama T, Lombardo FT. 2020. Understanding how complex terrain impacts tornado dynamics using a suite of high-resolution numerical simulations. J. Atmos. Sci. $77: 3277-300$

21. White FM, Xue H. 2021. Fluid Mechanics, NY, NY: McGraw Hill. 9th ed.

22. Kundu PK, Cohen IM. 2002. Fluid Mechanics, San Diego, CA: Academic Press. 2nd ed.

23. Hoecker WH. 1960. Wind speed and air flow patterns in the Dallas tornado of April 2, 1957. Mon. Weather Rev. $88: 167-80$

24. Garson Robert C, Catalán José Morlá, Allin CC. 1975. Tornado design winds based on risk. J of the Structural Division. 101 : 1883-97

25. Blevins RD. 1984. Applied fluid dynamics handbook, NY,NY: Van Nostrand Reinhold Co., Inc.

26. Coulbourne WL. 2008, Wind speed analysis of Greensburg, KS tornado. Presented at 2008 Structures Congress - Structures Congress 2008: Crossing the Borders, April 24-26, 2008, 314 : Vancouver, BC, Canada: ASCE

27. Edwards R, LaDue JG, Ferree JT, Scharfenberg K, Maier C, Coulbourne WL. 2013. Tornado intensity estimation: Past, present, and future. Bull. Amer. Meteor. Soc. 94 : 641-53 
28. McDonald JR, Mehta KC. 2004. A recommendation for an Enhanced Fujita scale (EFscale). Submitted to the National Weather Service (NWS), Lubbock, TX

29. Markee J, E. H., Beckerley JG, Sanders KE. 1974. Techinical basis for interim regional tornado criteria. US Atomic Energy Commission, Office of Regulation, Washington, DC

30. Doswell CA, Brooks HE, Dotzek N. 2009. On the implementation of the Enhanced Fujita scale in the USA. Atmos. Res. $93: 554-63$

31. White FM, Majdalani J. 2022. Viscous fluid flow, NY, NY: McGraw-Hill. 4th ed.

32. Buckingham E. 1916, Model experiments and the forms of empirical equations. Presented at ASME Transactions Spring Mtg., Buffalo, NY, June 1915, Paper no. 1487, 1916, 37 : 263. NY: ASME

33. Schmidlin T, Hammer B, King P, Ono Y, Scott Miller L, Thumann G. 2002. Unsafe at any (wind) speed? testing the stability of motor vehicles in severe winds. Bull. Am. Meteorol. Soc. $83: 1821-744$

34. Grams JS, Thompson RL, Snively DV, Prentice JA, Hodges GM, Reames LJ. 2012. A climatology and comparison of parameters for significant tornado events in the United States. Weather \& Forecasting. 27 : 106-23

35. Fish DW. 2007. Rhode island LRFD bridge design manual. RI Department of Transportation, Providence, RI 
36. Fish DW, Chahine GK. 2015. Bridge design standard details. Rhode Island Department of Transportation, Providence, RI

37. Lilly DK. 1969. Tornado dynamics. NCAR Manuscript 69-117; doi:10.5065/D64Q7RWT. $39 \mathrm{pp}$.

38. Fiedler BH, Rotunno R. 1986. A theory for the maximum windspeeds in tornado-like vortices. J. Atmos. Sci. 43: 2328-40

39. Katopodes ND. 2019. Chapter 7 - vorticity dynamics. In Free-Surface Flow, ed. ND Katopodes, 516-65. Butterworth-Heinemann

40. Nolan DS, Farrell BF. 1999. The structure and dynamics of tornado-like vortices. $J$. Atmos. Sci. 56: 2908-36

41. Rotunno R. 2013. The fluid dynamics of tornadoes. Annu. Rev. Fluid Mech. 45: 59-84

42. Bluestein HB, Ladue JG, Stein H, Speheger D, Unruh WF. 1993. Doppler radar wind spectra of supercell tornadoes. Mon. Weather Rev. $121: 2200-22$

43. Fiedler BH. 1994. The thermodynamic speed limit and its violation in axisymmetric numerical simulations of tornado-like vortices. Atmosphere-Ocean. 32 : 335-59

44. Garson Robert C, Morla-Catalan J, Allin CC. 1975. Tornado risk evaluation using wind speed profiles. J of the Structural Division. $101: 1167-71$

45. Baines WD. 1963, Effects of velocity distribution on wind loads and flow patterns on buildings. 1963, London: National Physical Laboratory 
46. Blasius H. 1908. Grenzschichten in flussigkeiten mit kleiner reibung. Zeitschrift für angewandte Mathematik und Physik. $56: 1-37$

47. Goldstein S. 1933. On the two-dimensional steady flow of a viscous fluid behind a solid body.-I. Proceedings of the Royal Society of London. Series A, Containing papers of a mathematical and physical character. $142: 545-62$

48. Schlichting H. 1979. Boundary-layer theory, New York [u.a.]: McGraw-Hill. 7th ed.

49. Schmitt, T.J. 1954. Wind-tunnel investigation of air loads on human beings. Navy Dept., US Dept of Defense, Washington, D.C. 


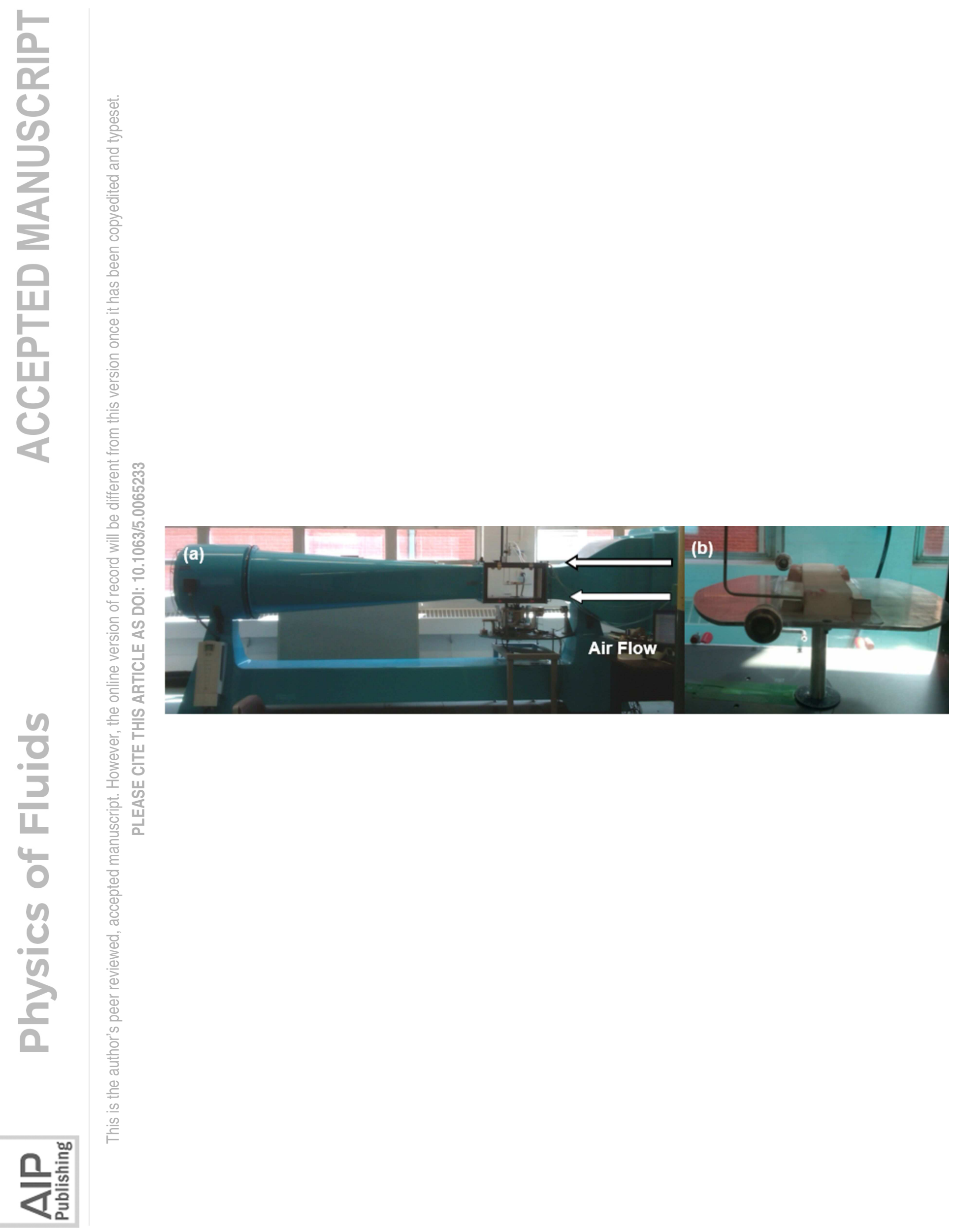




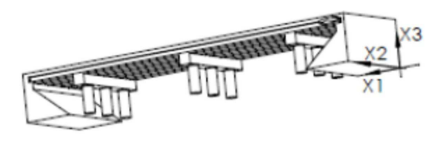

Pitot-static tube above

bridge - Loc1

LOCATION 1

Pitot-static tube between 1 . Beams - Loc2

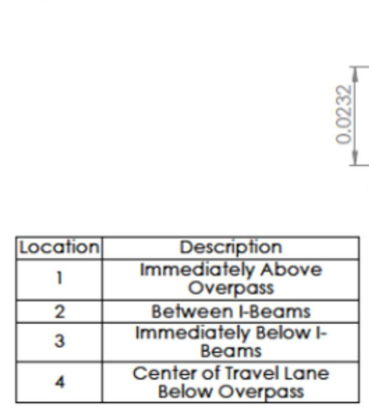

कृ

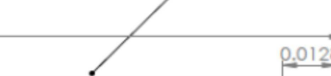

LOCATION

LOCATION 3

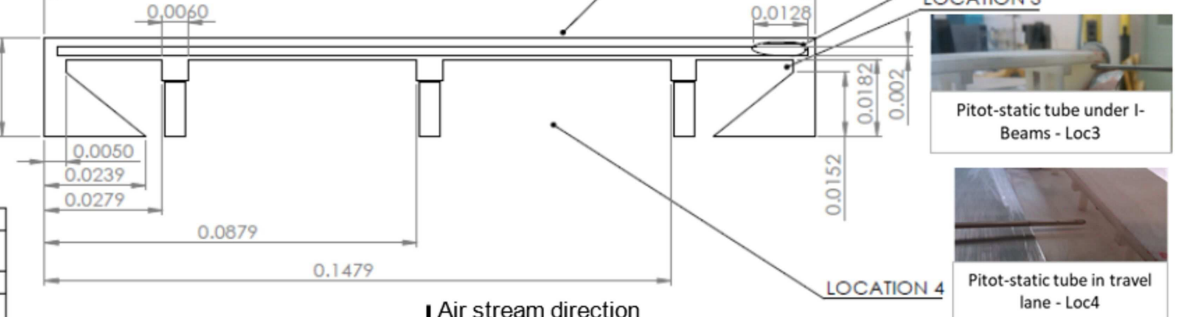

Air stream direction

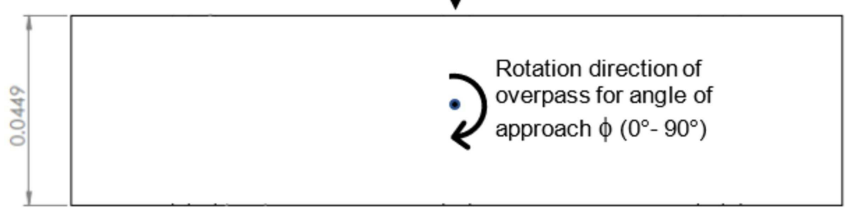



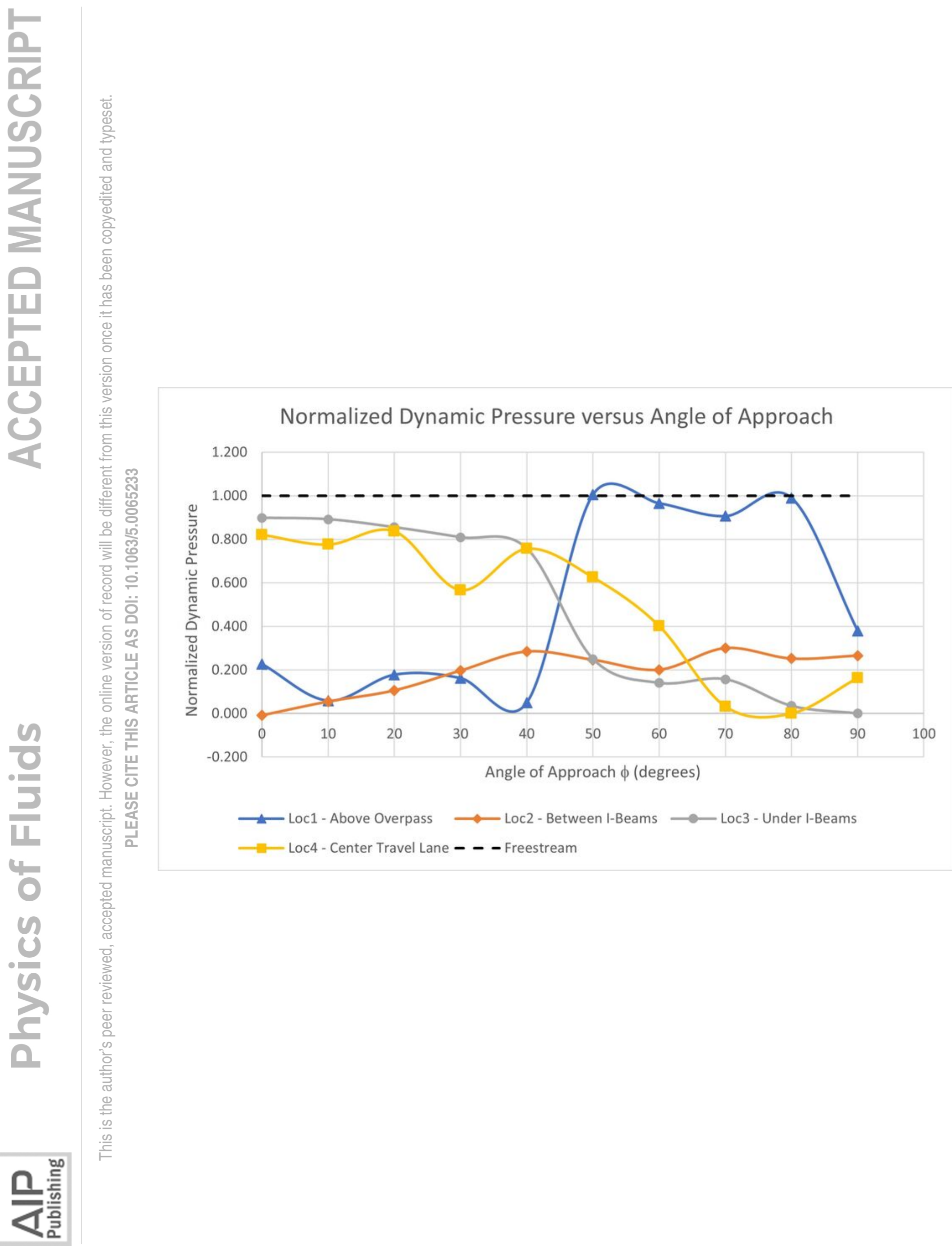


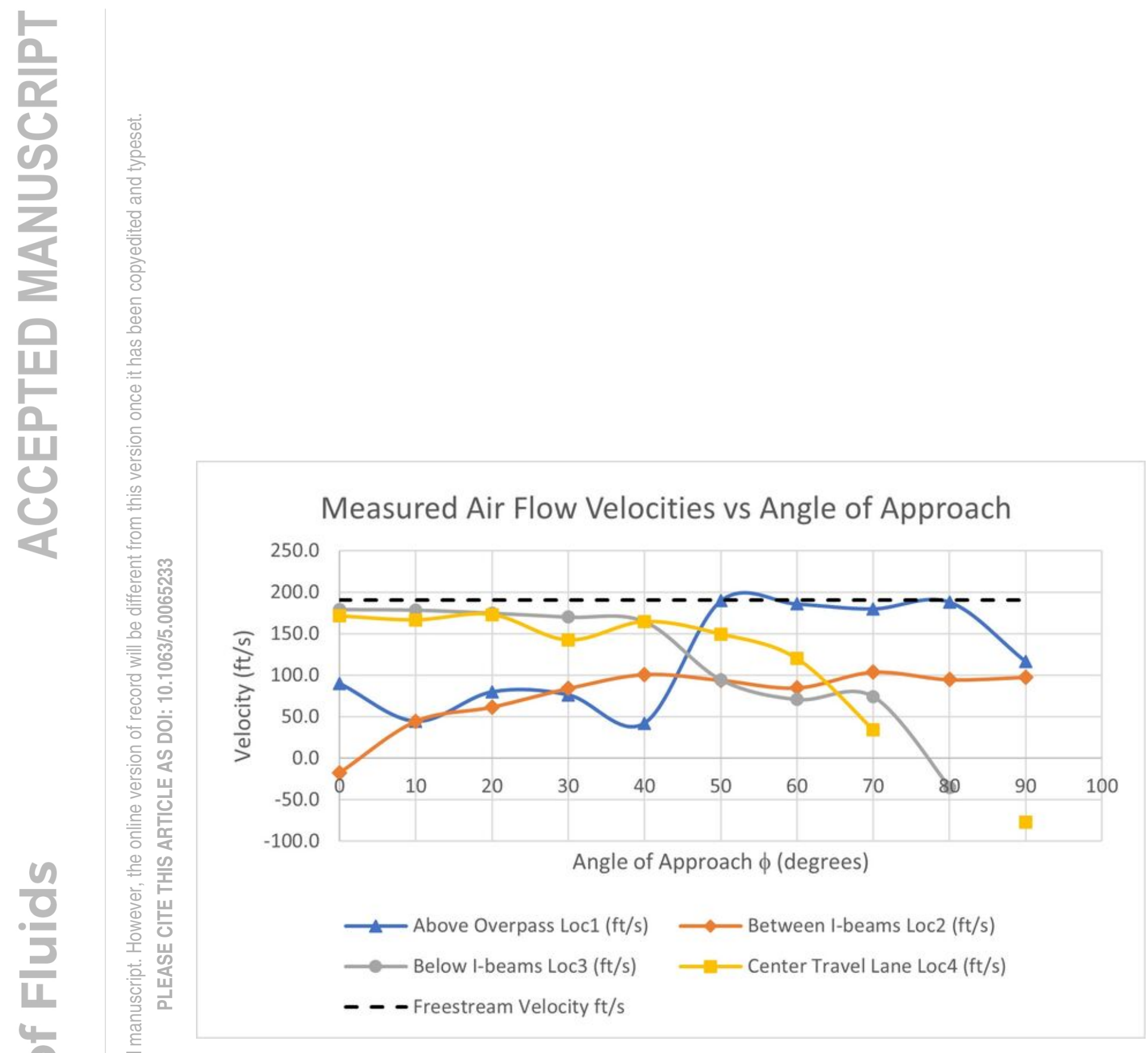




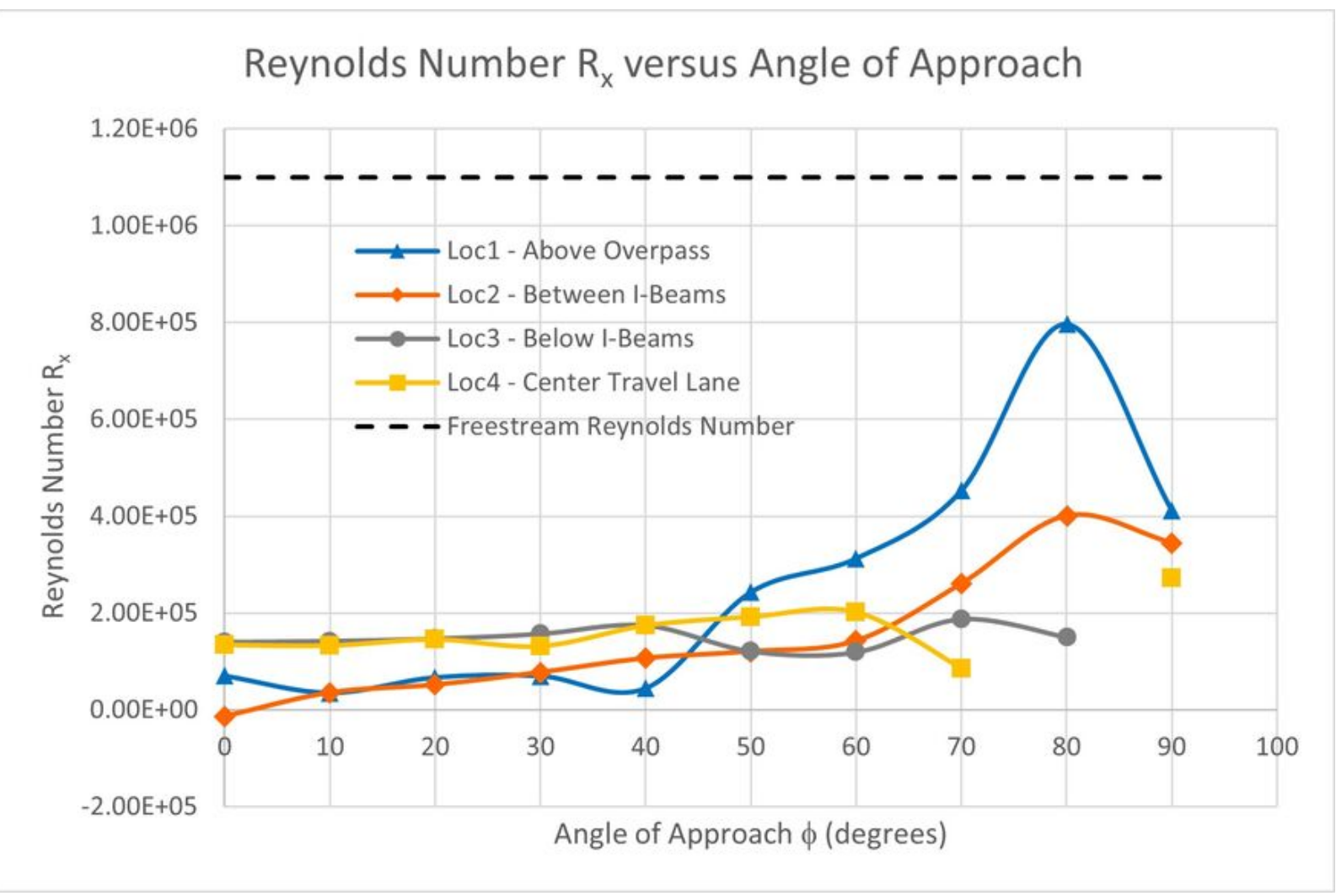



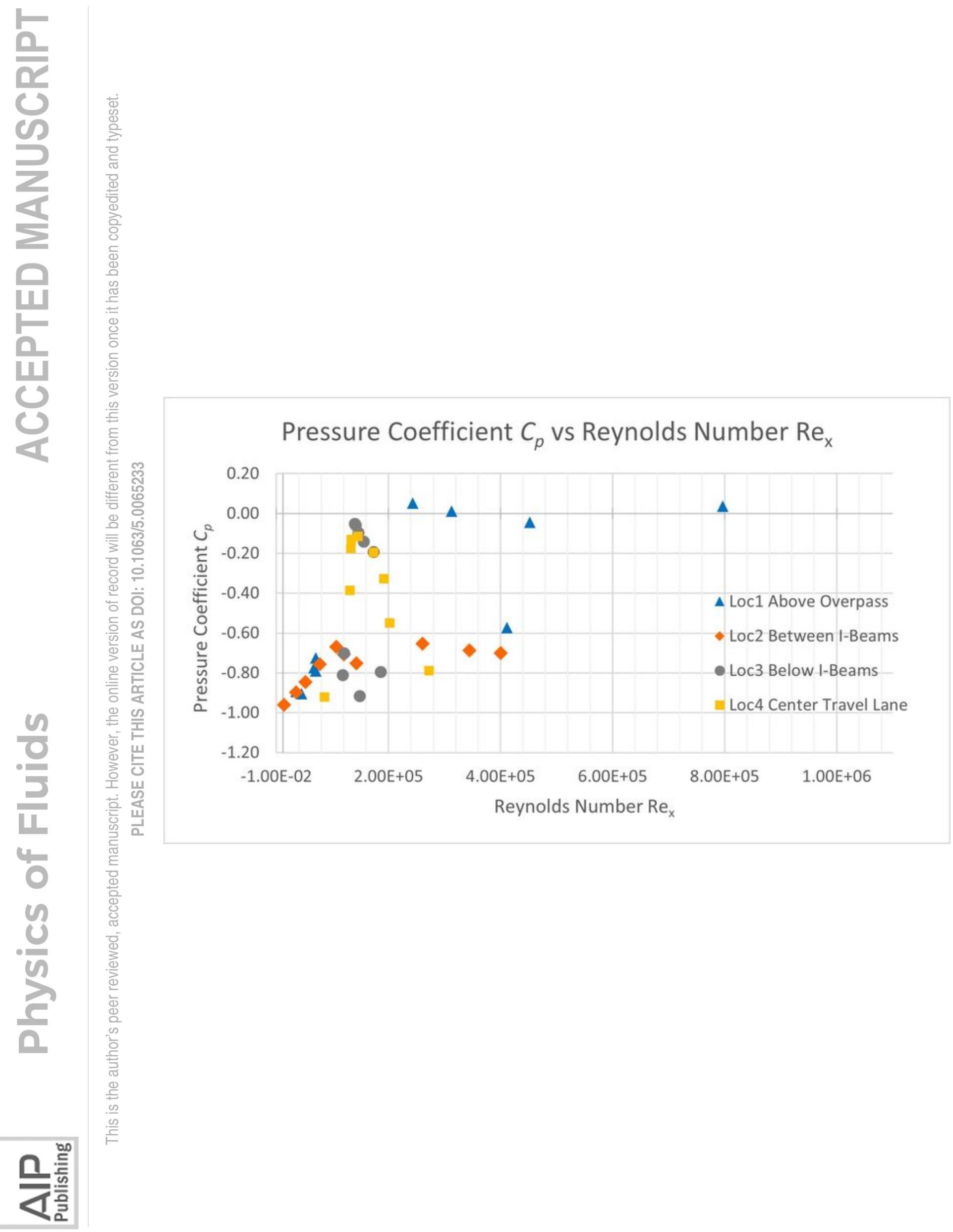


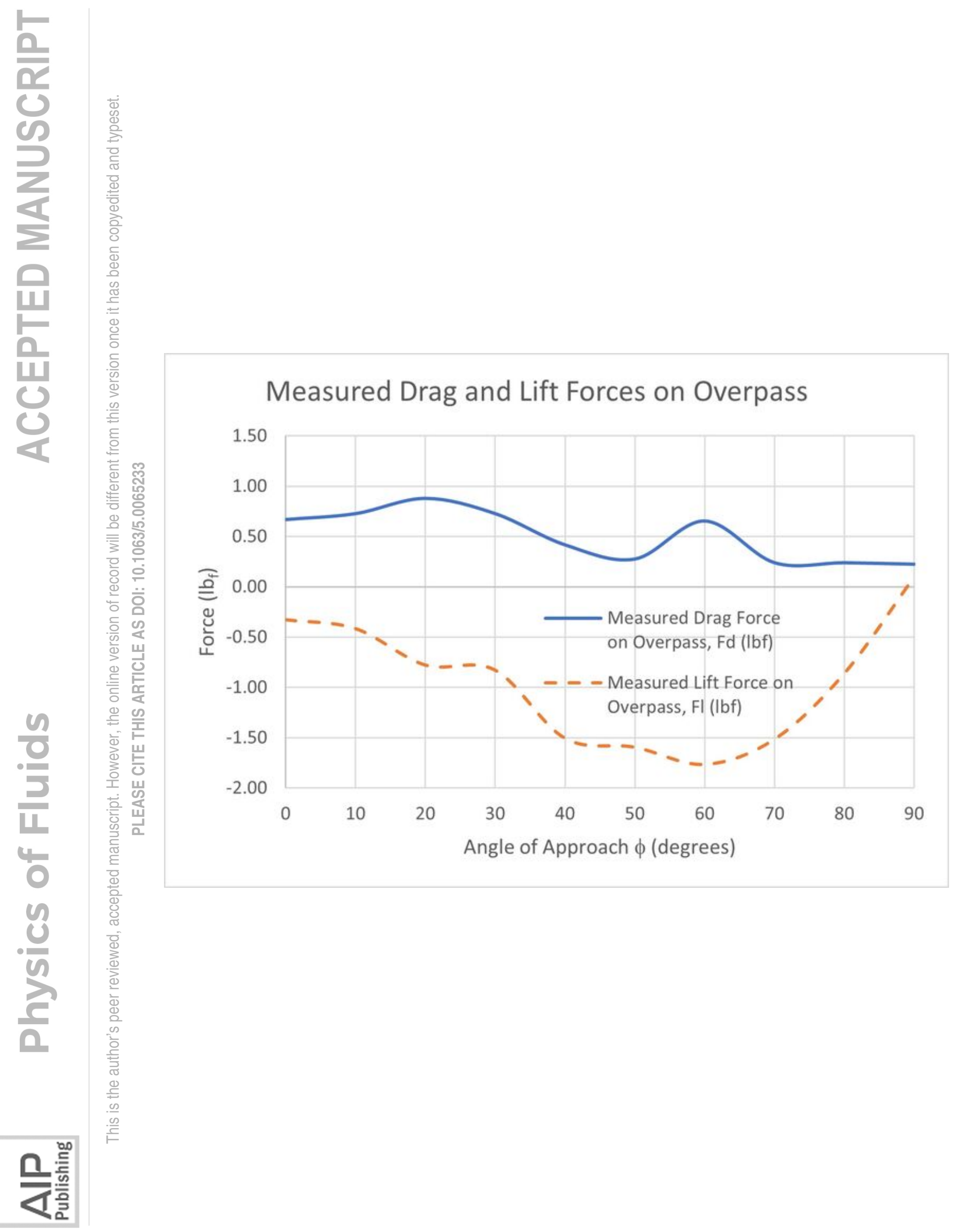




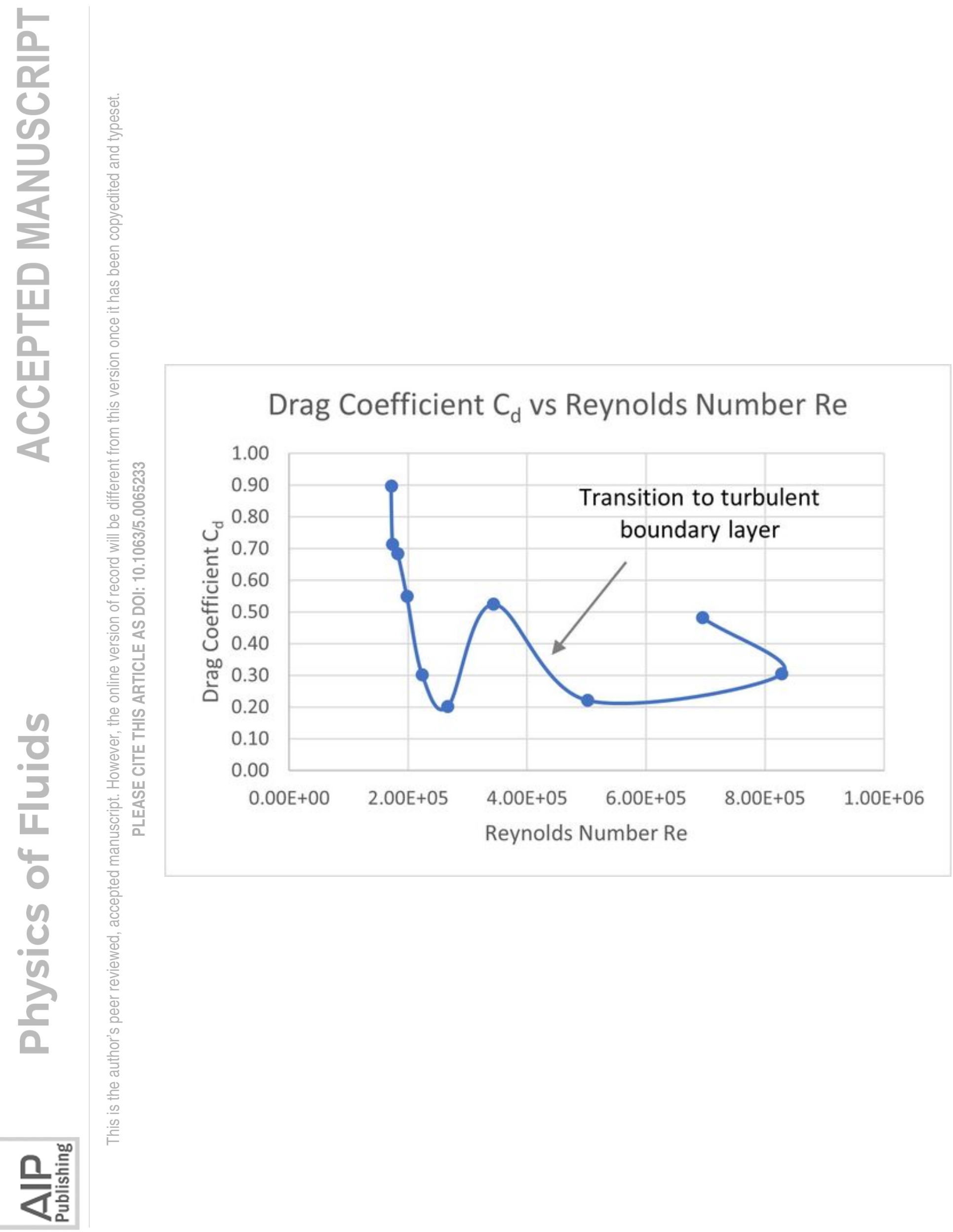




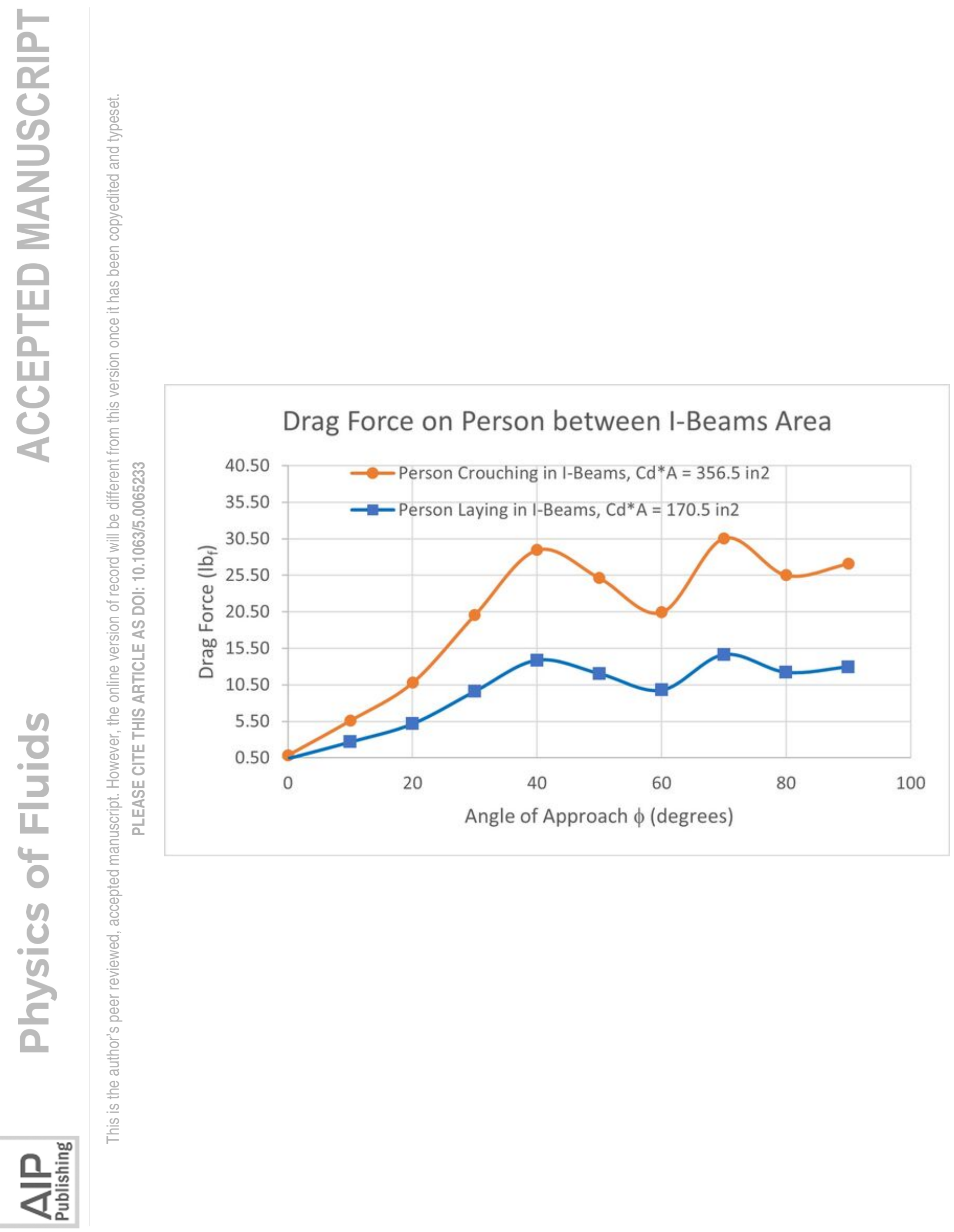

